\title{
Effects of Environmental Factors Growth Traits of Akkaraman Sheep in Çankırı Province
}

\author{
Sedat BEHREM ${ }^{1, *}$ \\ ${ }^{1}$ International Center for Livestock Research and Training, 06852, Lalahan, Ankara/TURKEY \\ *Corresponding author
}

Article History

Received: 22 February 2021

Accepted: 8 May 2021

First Online: 15 May 2021

\section{Corresponding Author}

E-mail: sedatbehrem1071@gmail.com

\section{Keywords}

Pre-weaning growth traits

Environmental factors

Akkaraman

Kleiber ratio

\begin{abstract}
Small ruminants are important contributors of food supply chains throughout the world. In this study, characterization of distributions of birth weight, weaning weight, average daily gain and Kleiber ratio as well as estimation of effects of certain environmental factors on these traits were aimed in Akkaraman sheep raised around Çankırı province. For this purpose, the linear mixed model was fitted to estimate the effect of factors and to obtain the least square means for the traits. The effect of all studied fixed factors on birth weight (BW), weaning weight (WW), average daily weight gain (ADWG) and Kleiber ratio (KR) were found to be significant. The male lambs have more BW and $W W$ than female lambs. The least square mean of ADWG for female lambs was found higher than male lambs. Additionally, the least square mean of the pre-weaning growth traits of single-born lambs were found to be higher than that of twin-born lambs. The birth weights of lambs born in January and February were higher than March. In general, the study reported that pre-weaning growth traits were affected by several environmental factors, which can be used for herd management practices aiming for higher productivity in Akkaraman sheep.
\end{abstract}

\section{Introduction}

Small ruminants are important contributors of food supply chains throughout the world. They are known for their high adaptive capacity under various environmental conditions such as meagre diet and arid landscapes. Compared to large ruminants, sheep and goats require less input of feed, water and labour, which provides the species to be spread out around various environments (Joy et al., 2020). Among those indigenous breeds have critical role in sustainable production and food security for various reasons such as genetic variability and high adaptation (Bingol, 2016). Nutrition of a large fraction of human population heavily depend on animal-sourced products such as meat and milk (Gül et al., 2020; Mondal \& Reddy, 2017).

Turkey -with 55 millions of small ruminants of which majority are indigenous breeds- is among the largest producers of small ruminants around the world (TUIK, 2020). There are a wide range of indigenous fat- and thin-tailed sheep breeds in Turkey (Aksoy et al., 2019;
Yilmaz \& Wilson, 2012). As a fat-tailed and combined production purpose breed, Akkaraman has a large share of sheep population in Turkey with low productivity (Ünal, 2002; Yalcin, 1986). Even though the number of farm animals is excessively high in Turkey, low productivity leads to the reduced amount of meat production per person. Therefore, increasing growth and productivity of sheep have a great importance for sustainable food supply and food security in Turkey (Şenyüz, 2020; Yardımcı \& Özbeyaz, 2001).

Similar to the other indigenous sheep, Akkaraman also suffered from the lack a systematic breeding programme until recently, with majority of the breed is still not subject to a genetic selection system. Therefore, farmers select their rams and ewes according to the morphological observations (Ceyhan et al., 2019). As a significant cultural component, sheep farming is majorly implemented as outdoor production based on meagre pasture. However, this approach is compromised in terms of identifying the genetic potential of animals. Recent studies showed high 
phenotypic variation in terms of productivity traits which also indicates a potential background genetic variation to build upon with selection (Biçer et al., 2019). A systematic selection approach initially requires characterising and ameliorating the effects of environmental factors which is followed by a genetic selection for a cumulative gain (Sönmez et al., 2009).

Lamb birth weight, weaning weight, feed efficiency and average daily gain are important indicators of productivity in sheep selection programmes. Additionally, Kleiber ratio is another indicator phenotype which is long used to monitor feed efficiency (Eskandarinasab et al., 2010; Jeichitra \& Ramanujam, 2014; Mahala et al., 2020; Supakorn \& Pralomkarn, 2012). There has been a substantial progress in Çankırı with the launch of Akkaraman community-based sheep breeding programme since 2011. It is conducted as a sub-project of "National Sheep and Goat Breeding Project under Farmers Condition" implemented by the Ministry of Agriculture and Forestry in collaboration with various universities, research institutes, sheep \& goat breeder associations and breeders. Birth weight, weaning weight and average daily gain of animals are routinely recorded as part of the project. Therefore, in this study, characterization of distributions of birth weight, weaning weight, average daily gain and Kleiber ratio as well as estimation of effects of certain environmental factors on these traits were aimed in Akkaraman sheep raised around Çankırı province.

\section{Materials and Methods}

\section{Animals and Phenotype}

The study was carried out on Akkaraman lambs which were born in 2014 and 2015 at 133 herds in the National Community-Based Small Ruminant Breeding Programme in Çankırı province, Turkey. Çankırı, located in the north of Central Anatolia, between Kızılırmak and the Western Black Sea main basins, is located between $40^{\circ} 30^{\prime}$ and $41^{\prime \prime}$ north latitudes and $32^{\circ} 30^{\prime}$ and $34^{\prime \prime}$ east longitudes. During the spring-summer period (from April to November) the animals were grazed on very poorquality pasture, and in the winter period, they were fed with an average of $0.6 \mathrm{~kg} /$ day of concentrate feed per animal in the pen. The lambs were weaned after approximately 90 days of nurturing period by their dams.

Birth weight (BW), weaning weight (WW), average daily weight gain (ADWG) and Kleiber ratio at weaning (KR) of approximately 19900 observations were obtained as traits. Additionally, birth and weaning dates, sex, birth type (singlets/twins) and birth month (January/February/March) were regularly recorded. Weaning weight was interpolated weights of the animals to 90 days which is average weaning day. Average daily weight gain (ADWG) was obtained via linear statistics by using BW and WW. Kleiber ratio at weaning (KR) was also calculated from ADWG and WW $\left(A D W G / W W^{0.75}\right)$. Detailed description of the data structure with the sample size after removing the outliers were presented in Table 1.

\section{Statistical Analyses}

The outliers of the observations (values exceeding mean \pm 3 standard deviation) were checked. Normality of the responses were tested with Shapiro-Wilk test. Moreover, the homogeneity of variance was visually inspected by plot obtained from residual vs fitted value of the responses. Initially, the effect of environmental factors (sex, birth type, birth month and birth year in this case) were tested to build final linear mixed models. The data management and all statistical analysis were performed using "Ime4", "ImerTest" and many other basic packages of $R$ statistical environment ( $R$ Core Team, 2020).

The linear mixed models were used to estimate the effect of environmental factors after to fit final models for the traits.

Table 1. Descriptive statistics of pre-weaning growth traits.

\begin{tabular}{|c|c|c|c|c|}
\hline Trait & BW (kg) & WW (kg) & ADWG (g) & KR \\
\hline Number of observations & 19.910 & 19.772 & 19.755 & 19.724 \\
\hline Mean & 4.19 & 24.13 & 221 & 20.01 \\
\hline Standard deviation & 0.93 & 6.64 & 73 & 2.63 \\
\hline Minimum & 1.50 & 10.68 & 56 & 12.22 \\
\hline Maximum & 6.97 & 44.39 & 438 & 26.82 \\
\hline Coefficient of Variation & 0.22 & 0.27 & 0.32 & 0.13 \\
\hline
\end{tabular}


The least square means of the factors was obtained from those mixed models. Herd and maternal permanent environmental effect were added the models as random factors. Subsequently, the differences between groups of the significant factors were tested with Duncan's Test. The final linear mixed models' description for the traits are given below:

Model: $\quad y_{i j k l}=\mu+s_{i}+t_{j}+m_{k}+y_{1}+z_{1} h+z_{2} p+e_{i j k l}$

Where $y_{\mathrm{ijk}}$ are the observations of the dependent variables (i.e., BW, WW, ADWG and KR); $\mu$ is the intercept; $s_{i}$ is the fixed effects of sex; $t_{j}$ is the fixed effects of birth type (2 levels); $t_{j}$ is the fixed effects of birth month ( 3 levels); $t_{j}$ is the fixed effects of birth year ( 2 levels); $Z_{1} h$ is the random herd effects; $Z_{2} p$ is the maternal permanent environmental effects and $e_{i j k l}$ is the residual error of observations in the models.

\section{Results and Discussion}

The effects of environmental factors such as sex, birth type, birth month, birth year, herd and maternal permanent environmental effects on BW, WW, ADWG and $K R$ of Akkaraman lambs were investigated in this study. With this purpose, the linear mixed models were fitted to estimate the effect of factors and to obtain the least square means for the traits. The diagnostic test of the models and the interaction between factors were also implemented. Finally, the multiple comparison tests were applied to obtain significance level of differences between groups of factors.

After building the appropriate final models, all factors had significant effect on the traits (see Table 2). According to the diagnostic tests, the data showed normal distribution and homogenous variance. In general, interactions between factors were not significant.

The effect of all studied fixed factors on birth weight (BW) were found to be significant. The least square means of sex were $4.23 \pm 0.03$ and $3.83 \pm 0.03$ for male and female lambs, respectively, represented in Table 2. Moreover, the difference between male and female groups was found to be statistically important ( $P$ < 0.001). In a study conducted by Ünal, (2002) between 1996 and 1997 on Akkaraman lambs, the mean birth weight of male and female lambs was found to be approximately 4.69 and $4.39 \mathrm{~kg}$, respectively. In another study conducted on Akkaraman lambs, corrected birth weights of male and female lambs were found to be 4.86 and $4.64 \mathrm{~kg}$, respectively (Çolakoğlu \& Özbeyaz, 1999). As in the present study and both studies discussed, it is seen that male lambs have 200 - $500 \mathrm{~g}$ more birth weight compared to female lambs. In the study, the birth weights of singlet and twin lambs were found as 4.41 \pm 0.03 and $3.66 \pm 0.03 \mathrm{~kg}$, respectively and the differences were statistically significant $(P<0.001)$. As predicted, in many studies conducted in the same breed, it was reported that the birth weight of single born lambs was higher than that of twin born and was statistically significant (Ceyhan et al., 2019; Çolakoğlu \& Özbeyaz, 1999; Ünal, 2002). In the study, the least square mean of the birth weights of lambs born in January, February and March were found to be $4.03 \pm$ $0.03,4.08 \pm 0.03$ and $3.98 \pm 0.04 \mathrm{~kg}$ respectively. Moreover, the difference between the groups was found to be significant in the multiple comparison test between these months. In a study conducted by Gül et al., (2020), similar results were obtained in the average birth weight of Awassi lambs in January, February and March. The seasonal pattern revealed that the birth weight of lambs born in January and February was relatively higher than that of lambs born in March. The possible reason for this situation is thought to be that the dams of lambs born in March were exposed to more feed shortness in the last trimester of pregnancy. Table 2 also illustrate that the least square means of BW of lambs born in 2014 and 2015 were $3.94 \pm 0.04$ and 4.13 $\pm 0.06 \mathrm{~kg}$ respectively and it was significant $(P<0.001)$. This result from the study contribute that the feeding and many other strategies applied on herds are quite important on the birth weight of lambs.

Similar to BW, all fixed effects were significant on WW of lambs in the study. The detail information and the least square means of WW were present in Table 2. The least square means of WW of male and female lambs are $23.52 \pm 0.22$ and $23.36 \pm 0.22 \mathrm{~kg}$, respectively, while the least square means of WW of single and twin lambs are $24.98 \pm 0.22$ and $21.89 \pm 0.23 \mathrm{~kg}$, respectively. Moreover, the least square mean of the lambs born in January, February and March are $20.97 \pm 0.23,24.37 \pm$ 0.23 and $24.98 \pm 0.25 \mathrm{~kg}$, respectively. The effect of sex, birth type and birth month on WW were found to be significant. As a result of the multiple comparison test between the birth month groups, it was seen that the difference between the groups were significant. Similar result for the effects of sex, birth type and birth month are generally reported in the studies (Çolakoğlu \& Özbeyaz, 1999; Ünal, 2002). Although there is a slight difference between the weaning weight of male lambs and female lambs, this difference was found to be statistically significant in the present study and many other studies. Additionally, in the studies reported in Akkaraman lambs, the WW of the single-born lambs were found higher than the twin-born lambs as in the study. The WW of lambs born in February and March in the study were higher than those born in the January, but in the study conducted by Gül et al., (2020) in Awassi lambs the WW of the lambs born in March were lower than those born in February and January. This situation is thought to be due to the difference in breed and the seasonal conditions of the different geography and pasture where the lambs are raised. 
Table 2. The least square means $( \pm S E)$ of the pre-weaning traits in Akkaraman lambs.

\begin{tabular}{|c|c|c|c|c|c|c|}
\hline \multirow[b]{2}{*}{ Fixed Effects } & \multicolumn{3}{|c|}{ BW (kg) } & \multicolumn{3}{|c|}{ WW (kg) } \\
\hline & $n$ & $\mathrm{LSM} \pm \mathrm{SE}$ & $p$-value & $n$ & $\mathrm{LSM} \pm \mathrm{SE}$ & $p$-value \\
\hline Sex & & & $* * *$ & & & $*$ \\
\hline Male & 10104 & $4.23 \pm 0.03^{a}$ & & 10031 & $23.52 \pm 0.22^{\mathrm{a}}$ & \\
\hline Female & 9806 & $3.83 \pm 0.03^{b}$ & & 9741 & $23.36 \pm 0.22^{b}$ & \\
\hline Birth type & & & $* * *$ & & & $* * *$ \\
\hline Single & 14440 & $4.41 \pm 0.03^{a}$ & & 14331 & $24.98 \pm 0.22^{\mathrm{a}}$ & \\
\hline Twin & 5470 & $3.66 \pm 0.03^{b}$ & & 5441 & $21.89 \pm 0.23^{b}$ & \\
\hline Birth month & & & $* * *$ & & & $* * *$ \\
\hline January & 8439 & $4.03 \pm 0.03^{b}$ & & 8438 & $20.97 \pm 0.23^{c}$ & \\
\hline February & 7781 & $4.08 \pm 0.03^{a}$ & & 7733 & $24.37 \pm 0.23^{b}$ & \\
\hline March & 3690 & $3.98 \pm 0.04^{c}$ & & 3601 & $24.98 \pm 0.25^{\mathrm{a}}$ & \\
\hline Birth year & & & $* * *$ & & & $* * *$ \\
\hline 2014 & 12840 & $3.94 \pm 0.04^{b}$ & & 12724 & $24.63 \pm 0.25^{\mathrm{a}}$ & \\
\hline 2015 & 7070 & $4.13 \pm 0.06^{a}$ & & 7048 & $22.24 \pm 0.36^{b}$ & \\
\hline
\end{tabular}

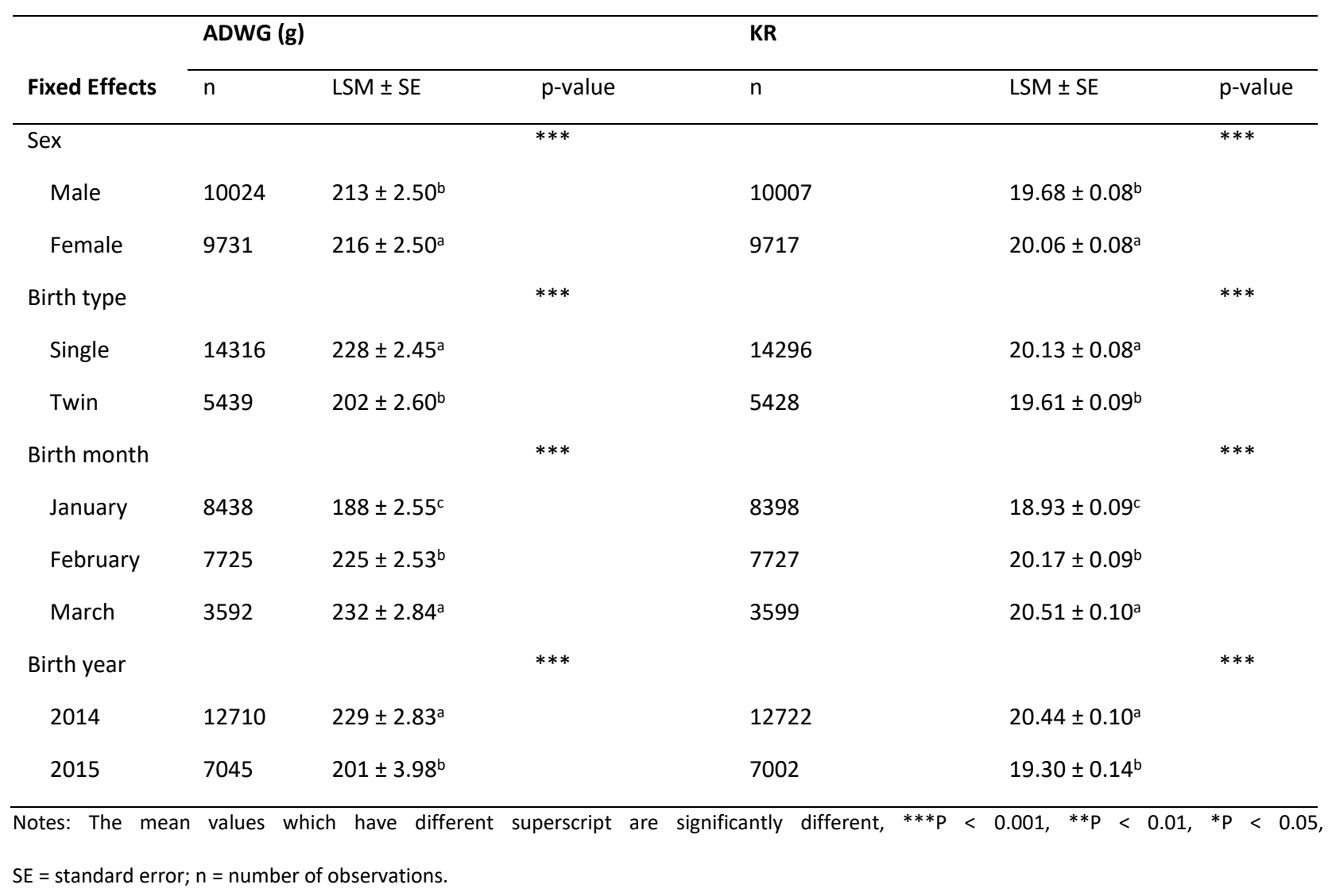


In Table 2 the effects of year were also illustrated, the least square means of WW lambs born in 2014 and 2015 were $24.98 \pm 0.22$ and $21.89 \pm 0.23 \mathrm{~kg}$ respectively and it was significant $(P<0.001)$. This result from the study contribute that the different conditions of pasture in different years are crucially important factor on WW. When the dams of lambs were graze on the pasture with good conditions, their nursing ability is becoming better.

The effect of sex, birth type, birth month and birth year were found significant on ADWG similar to $B W$ and WW. The least square means of ADWG for male lambs and female lambs were $213 \pm 2.50$ and 216 $\pm 2.50 \mathrm{~g}$, while the least square means of ADWG for single-born lambs and twin-born lambs were found to be $228 \pm 2.45$ and $202 \pm 2.60 \mathrm{~g}$, respectively. The ADWG of lambs born in February were lower than those born in February and March. ADWGs by month are $188 \pm$ $2.55,225 \pm 2.53$ and $232 \pm 2.84$ g, respectively. Interestingly, in the present study, ADWG of female lambs was slightly higher than that of males. In the study conducted by Ceyhan et al. (2019) on Akkaraman lambs, it was reported that the ADWG of male lambs were higher than that of females. In the same study, ADWG of single-born lambs were higher than twinborn lambs. This result was consistent with the present study.

The least square mean of KR for BW was found $19.68 \pm 0.08$ and $20.06 \pm 0.08$ for male and female lambs, respectively. In a study conducted in Mecheri sheep, as in the current study, the KR was found to be higher in male lambs than in female lambs. The KR values in the study are $13.23 \pm 0.08$ and $12.91 \pm 0.08$ in male and female lambs, respectively (Jeichitra \& Ramanujam, 2014). KR rates of single-born and twinborn lambs are $20.13 \pm 0.08$ and $19.61 \pm 0.09$, respectively in this study. In the study conducted by Mahala et al. (2020) on Avikalin lambs, mean Kleiber ratio was calculated as 16.8 for average daily weight gain until weaning.

\section{Conclusion}

In the study, all of the fixed effects used in the analysis were found to be very effective on preweaning growth parameters (BW, WW and ADWG) and Kleiber ratio (KR), which is the indicator of the feed conversion parameter. The results of the current study generally showed that male lambs have more BW and WW than female lambs. Surprisingly, for ADWG the least square mean was found higher in female lambs than males. Additionally, the least square mean of the pre-weaning growth traits of single-born lambs were found to be higher than that of twin-born lambs. The birth weights of lambs born in January and February were higher than March. It has been observed that herd and nutrition management, climate and pasture condition in different years have an effect on birth weight, weaning weight and daily live weight of lambs. The Kleiber ratio, which is an indicator of feed utilization, was higher in male and single lambs than in female and twin lambs. It was observed that the KR of lambs born in January were lower than lambs born in February and March.

In general, the study reported that pre-weaning growth traits were affected by environmental factors. Therefore, it has been observed that productivity increases can be achieved in animals by improving environmental conditions. Especially determining the birth months in accordance with the feeding strategy can provide the most effective improvement.

In order to examine the pre-weaning traits of Akkaraman sheep in more detail, the most important recommendation put forward in our study is to implement further effect size estimation studies, estimate the heritability of these traits by using full pedigree and to develop the breed genetically in addition to environmental factors.

\section{Acknowledgements}

The study population, Akkaraman Breeding Programme of the National Community-Based Small Ruminant Breeding Programme, with the project batch numbers of (TAGEM/18AKK2011-2012). The author kindly acknowledges the General Directorate of Agricultural Research and Policies (Ministry of Agriculture and Forestry) of the Republic of Turkey, who fund and run the National Community Based Small Ruminant Breeding Programme for all contribution.

\section{References}

Aksoy, Y., Çiçek, Ü., Sen, U., Åžirin, E., Ugurlu, M., Önenç, A., Kuran, M., \& Ulutas, Z. (2019). Meat production characteristics of Turkish native breeds: II. meat quality, fatty acid, and cholesterol profile of lambs. Archives Animal Breeding, 62(1), 41-48. https://doi.org/10.5194/aab-62-41-2019

Biçer, O., Keskin, M., Gül, S., Gündüz, Z., Oflaz, N. Z., \& Behrem, S. (2019). Comparison of yield characteristics of brown and black headed Awassi sheep. Mustafa Kemal University Journal of Agricultural Sciences, 24(1), 58-61.

Bingol, E. (2016). Survival Rates of Lambs, Greasy Fleece Weight and Live Weight at Parturition of Fat-Tailed Hamdani Sheep Grown in East Anatolia Region of Turkey. Van Veterinary Journal, 27(1), 1-4.

Ceyhan, A., Şekeroğlu, A., \& Deman, M. (2019). Some reproductive traits and lambs growth performance of Akkaraman sheep raised in Niğde province. Turkish Journal of Agriculture-Food Science and Technology, 7(10), 1509-1514. https://doi.org/ 10.24925/turjaf.v7i10.1509-1514. 2249

Çolakoğlu, N., \& Özbeyaz, C. (1999). Comparison of some production traits in Malya and Akkaraman sheep. Turkish Journal of Veterinary and Animal Sciences, 23(4), 351-360.

Eskandarinasab, M., Ghafouri-Kesbi, F., \& Abbasi, M. A. (2010). Different models for evaluation of growth 
traits and Kleiber ratio in an experimental flock of Iranian fat-tailed Afshari sheep. Journal of Animal Breeding and Genetics, 127(1), 26-33. https:// doi.org/10.1111/j.1439-0388.2008.00789.x

Gül, S., Keskin, M., Biçer, O., Gündüz, Z., \& Behrem, S. (2020). Effects of different lambing season on some reproductive characteristics of ewes and growth performance of lambs in Awassi sheep. Lalahan Hayvancılık Araştırma Enstitüsü Dergisi, 60(1), 32-36. https://doi.org/10.46897/lahaed. 779729

Jeichitra, V., \& Ramanujam, R. (2014). Kleiber ratio in Mecheri sheep. The Indian Veterinary Journal, 91, 17-19.

Joy, A., Dunshea, F. R., Leury, B. J., Clarke, I. J., Digiacomo, K., \& Chauhan, S. S. (2020). Resilience of small ruminants to climate change and increased environmental temperature: A review. Animals, 10(5). https://doi.org/10.3390/ani 10050867

Mahala, S., Saini, S., Kumar, A., Sharma, R. C., \& Gowane, G. R. (2020). Genetic trends for the growth rates and Kleiber ratio in Avikalin sheep. Small Ruminant Research, 189, 106143. https:// doi.org/10.1016/ j.smallrumres.2020.106143

Mondal, S., \& Reddy, I. J. (2017). Impact of climate change on livestock production. Biotechnology for Sustainable Agriculture: Emerging Approaches and Strategies, 234-256. https://doi.org/10.1016/ B978-0-12-8121603.00008-8

R Core Team. (2020). R: A language and environment for statistical computing. R Foundation for Statistical Computing, Vienna, Austria.

Şenyüz, H. H. (2020). Kuzu ve Buzağılarda Süzek Yemleme Uygulamalarının Yararları. Journal of Bahri Dagdas Animal Research, 9 (1):39-46.

Sönmez, R., Kaymakçı, M., Eliçin, A., Tuncel, E., Wassmuth, R., \& Taşkın, T. (2009). Türkiye koyun ıslahı çalışmaları. Journal of Agricultural Faculty of Uludag University 23(2), 43-65. https://doi.org/ 10.20479/uuzfd.09856

Supakorn, C., \& Pralomkarn, W. (2012). Genetic parameter estimates for weaning weight and Kleiber ratio in goats. Songklanakarin Journal of Science and Technology, 34(2), 165-172.

TUIK. (2020). Livestock production, number of sheep and goat. https://data.tuik.gov.tr/Kategori/ GetKategori?p=tarim-111\%7B\%5C\&\%7Ddil=1

Ünal, N. (2002). Akkaraman ve Sakız x Akkaraman F1 kuzularda yaşama gücü, büyüme ve bazı vücut ölçüleri. Turk J Vet Anim Sci, 26, 109-116.

Yalcin, B. C. (1986). Sheep and goats in Turkey. The Food and Agriculture Organization (FAO).

Yardımcı, M., \& Özbeyaz, C. (2001). A Study on the comparison of the milk yield and udder characteristics in Akkaraman and Sakız $x$ Akkaraman Fı crossbreds. Lalahan Hay. Arşt. Derg. 41 (2) $63-77$.

Yilmaz, O., \& Wilson, R. T. (2012). The domestic livestock resources of Turkey: Economic and social role, species and breeds, conservation measures and policy issues. Livestock Research for Rural Development, 24(9), 6. 